\title{
STUDY ON PATHOPHYSIOLOGY AND MANAGEMENT OF SUPPURATIVE DISEASES OF PERIANAL REGION
}

Sudhakar Jena ${ }^{1}$, Siba Prasad Dash², Subhabrata Das³, Ramanarayan Sahu ${ }^{4}$

\section{HOW TO CITE THIS ARTICLE:}

Sudhakar Jena, Siba Prasad Dash, Subhabrata Das, Ramanarayan Sahu. "Study on Pathophysiology and Management of Suppurative Diseases of Perianal Region". Journal of Evolution of Medical and Dental Sciences 2014; Vol. 3, Issue 03, January 20; Page: 733-741, DOI: 10.14260/jemds/2014/1894

ABSTRACT: The perianal suppurative diseases (perianal abscess, fistula in ano, pilonidal sinus, hidradenitis suppurativa, Fournier's gangrene) is commonly encountered problem in surgery and the treatment of these diseases often make challenge for the surgeons as there is no single technique appropriate for its treatment. The objective of this study was to determine the incidence, pathophysiology and management of various types of these diseases. In this study, total 100 patients of perianal suppurative diseases from July 2011 to June 2013 were studied according to their distribution among the age, sex, socio-economic status, presenting features, organisms isolated, different treatment options and recurrences, and duration of diseases etc. and recorded. The overall morbidity in the study group was high. Significant risk factors in the analysis included low socioeconomic status, duration of presenting symptoms, types of disease, plan of treatment policy adopted and stage of the disease and some atypical forms. All the patients were emergency patients and immediate intervention with proper evaluation had been managed to change the fate of these patients. But the drawn conclusion from those studies was progress in pharmacology and other treatment specialties have so to say failed to extradicate these types of diseases till date.

KEY WORDS: perianal suppurative diseases. Perianal abscess. Fistula in ano. Pilonidal sinus. Hidradenitis suppurativa. Fournier's gangrene.

INTRODUCTION: The pathophysiology, diagnosis and management of suppurative diseases in perianal region can be a challenge for physicians. Abscess, fistula, pilonidal cyst and abscesses, hidradenitis suppurativa and sexually transmitted diseases are most common of these modalities and will be addressed with their guidelines. ${ }^{1}$

Most anorectal infections originate in the cryptoglandular area located in the anal canal at the level of dendateline. Cryptoglandular obstruction may result in four type of abscesses; perianal, ischiorectal, intersphincteric and supralevator. Small number of anorectal abscesses may have noncryptoglandular etiology such as in crohn's disease, atypical infections like tuberculosis, lymphogranuloma venerum, malignancy or trauma. Recently community acquired MRSA have been cultured more frequently from perianal abscess, but it is basically attached in skin infestation like in hidradenitis, particularly virulent organisms, immunological deficiency in the patient (e.g.: poorly controlled DM, HIV, obesity or localized scarring from previous operations) make the diagnosis more challenging; Fever, rigor, shock, may occur before subtle localized findings than pain and swelling; Bleeding, purulent discharge and fever may also be present. Delay in diagnosis and treatment may result in progression to local gangrene in these atypical patients. So the long term outcome of patients who progress to Fournier's gangrene (mixed infections with tissue necrosis) is poor. ${ }^{2}$

A perianal abscess is usually evident at the anal verge and patients present with rapid onset of acute pain at anal margin. An inflammatory process in the soft tissues of inner aspect of the buttock 
would more commonly indicate a perirectal or ischiorectal abscess. These abscesses present more slowly at the times over several days. Skin changes may be slow to appear as well. Pelvic pain, dysuria may herald a supralevator abscess. Constant pelvic or rectal pain which is exacerbated by defecation but associated with no external findings is more typical of intersphincteric process which extends cephaloid from the dentate line in the space between the circular muscle fibres of the internal sphincter and the longitudinal muscle fibres of rectal wall. ${ }^{3}$

Progression of a cryptoglandular disease chronic phase results in fistula-in-ano. The majority of patients with a fistula-in-ano have a history of abscess development with persistent discharge, pain and possibly bleeding. The external opening on the skin is evident, and digital rectal examination, anoscopy or proctoscopy may reveal an indurated area in the anal canal corresponding to the internal opening. If there is suspicion of any underling disease such as crohn's or immunosuppression additional diagnostic studies should be undertaken prior to formal treatment of fistula. ${ }^{2}$

Pilonidal cysts initially present as an abscess and or cellulitis in sacrococcygeal area. They are twice as common in men and present at mean ages of 21 and 19 years respectively. Affected individuals tend to be more hirsute. Spontaneous drainage often occurs through the dome of abscess cavity away from the midline followed by chronic drainage from the secondary sinuses. Some of the sinuses may tract towards the anus potentially confused with a fistula-in-ano or hidradenitis suppurativa. Hidradenitis suppurativa results from infections of occluded apocrine sweat glands. It is most commonly seen in the 2 nd to 4 th decade of life and is thought to be hormonally influenced with women affected three times as frequently as men. ${ }^{2}$

\section{AIMS AND OBJECTIVES:}

- To find out the incidence of suppurative diseases of perianal region among the patients of perianal diseases in cases presenting to surgery OPD of M.K.C.G.M.C.H, Berhampur.

- To study the epidemiology and etiological factors associated with perianal suppurative diseases.

- To study the classification and incidences of different perianal suppurative diseases.

- To study the different treatment modalities and their outcome on perianal suppurative diseases.

\section{MATERIAL AND METHODS:}

INCLUSION CRITERIA: This study will be carried out in patients presented to SURGERY OPD of M.K.C.G Medical College and Hospital from July 2011 to July 2013. The patients are chosen with previously described criteria (signs and symptoms) which belong to this wide spectrum of suppurative diseases of perianal region.

After reception at outdoor department, all the patients are registered and their brief physical examination is carried out with adequate privacy and consent and also for female patients in the presence of a female attendance/ nurse. Then they are referred to their respective surgical units. After detailed assessment of cases final diagnosis will be made.

EXCLUSION CRITERIA: The diseases of perianal region not presented as suppurative lesions like fissure, bleeding piles etc. are excluded from the study. The patients who are not willing to take part in the study or doing investigations or taking treatment or follow up excluded from the study. 
According to situation, pre-operative antibiotics, then surgery should be done. The patient should be follow up and re assessment done to know the effectiveness of our treatment on the patient.

DIAGNOSIS: While history and detailed physical examination are sufficient to diagnose majority of simple abscesses or fistulae, but patients with h/o crohn's disease, rectal cancer, pelvic irradiation, complicated fistula, recurrent perirectal infection, diabetes, immunosuppression, neutropenia, presence of horseshoe abscess, supralevator or abdominopelvic abscess may benefit from adjunctive imaging like:-CT scan or MRI scan. ${ }^{1}$

TREATMENT: For perianal or ischio-rectal abscess:-simple radical incision or cruciate incision of adequate size to un-roof the cavity and allow the complete drainage of purulent material as close to anal verge as possible. ${ }^{1}$

Operative goals for superficial, perianal, intersphincteric or superficial transphincteric anal fistulae are to open the tract and remove the epithelial lining by curettage, electrocautery, etc. ${ }^{2}$ More complex tracts involving a significant amount of sphincter muscle requires different surgical technique to avoid division of sphincteric muscle and resulting incontinence. These more complex fistulae may be treated with non-cutting seton, ${ }^{1}$ fibrin glue ablation, ${ }^{4-8}$ anal fistula plugs, ${ }^{9-12}$ rectal advancement flaps ${ }^{13-15}$ or combination of these.

For perianal pilonidal cyst and sinus: When presenting in the acute phase with redness, swelling, tenderness and fluctuance, drainage of the offending abscess can often be accomplished in the office. Antibiotics are not necessary. The incision should always be made off the midline, and drainage should be assured in the standard fashion as for any abscess. Importantly, any contained hair and debris should be removed from the abscess cavity, and any loculations should be disrupted.

When a chronic sinus has developed, multiple options are available for definitive treatment. Generally, healing is expected in 30-60 days, and recurrence is in the range of approximately 15\%, with the exception of marsupialization, which has the lowest recurrence rate of approximately $5 \%$. In the majority of cases, treatment under some form of anesthesia will be required. In perhaps the least invasive method, the sinuses are excised individually and closed primarily, and the deep cavity is curetted via a lateral incision, which is left open and packed. A second technique involves excising the anterior aspect of the cyst, with curettage of the base of the cyst. In a third technique, the entire cyst is excised down to sacral fascia and then packed open. In a fourth technique, after excision of the entire cyst, the edges of the wound are marsupialized to the deep tissue, which in most reports decreases healing time and recurrence.

- For complex or recurrent disease.

In a small subset of patients, despite adequate surgical technique, persistent or recurrent pilonidal disease defies cure. Three possibilities account for this.

1. A diverticulum of the main channel has been over-looked at primary operation.

2. New hairs enter the skin or scar.

3. When natal fold is deformed by scarring, the least trauma causes tearing of the scar, the resulting crevice becomes contaminated with coliform and cutaneous bacteria. 
Sound closure to one side of the midline can circumvent the incidence of recurrence. Other technique is said to be have high incidence of success. This involves an incision lateral to midline, which allows the abscess cavity to be scrubbed free of hair and granulation tissue. Removal of small midline pits is carried out with small incisions. The latter wound is then left open, but midline incisions are closed. In these patients, more advanced plastic techniques aimed at replacement of the midline tissue with skin flaps and grafts (e.g., Z-plasty, myo-cutaneous flaps) has led to healing in the majority of cases. So on summarizing of treatment of Pilonidal cyst and abscess-Acute Phase;-Simple incision and drainage to unroof the lateral extension of abscess but in Chronic Phase- A number of surgical techniques that are primary closure, healing by secondary intention......all gluteal cleft pits are removed. 16

Hidradenitis suppurativa:-operative drainage, local symptomatic therapy and antibiotics for cellulitis in initial phase.....wound healing by secondary intention is achieved by complete excision of affected skin...Vacuum dressing therapy or tissue transfer may be necessary for healing in extreme cases. Surgical management of chronic HS involves one of four possible techniques:

1. Unroofing and curettage of cavities and tracks with healing by secondary intention;

2. Wide excision and healing by secondary intention, with or without marsupialization;

3. Excision and primary closure;

4. Excision and split thickness skin grafting or advancement flap closure.

Of these techniques, wide local excision with healing by secondary intention is the most commonly used, though for very large wounds, some form of post-excision grafting is appropriate and may significantly accelerate healing. In order to optimize the healing of complicated wound closures especially near the anus, a temporary diverting colostomy should be considered. ${ }^{16}$

OBSERVATION: This study comprises of 100 perianal suppurative disease cases. They comprise of anorectal abscess (perianal abscess, ischio-rectal abscess, submucous abscess, pelvi-rectal abscess) 60 in numbers, pilonidal sinus 4 in number, perianal sinus/fistula-in-ano 28 in number, Fournier's gangrene 8 in number.

\begin{tabular}{|c|c|c|c|c|}
\hline $\begin{array}{c}\text { Age group } \\
\text { (in yrs.) }\end{array}$ & $\begin{array}{c}\text { Ano rectal abscess } \\
\text { (in \%) }\end{array}$ & $\begin{array}{c}\text { Fistula in Ano } \\
\text { (in \%) }\end{array}$ & $\begin{array}{c}\text { Pilonidal sinus } \\
\text { (in \%) }\end{array}$ & $\begin{array}{c}\text { Fournier's gangrene } \\
\text { (in \%) }\end{array}$ \\
\hline $0-9$ & $1(1.67)$ & 0 & 0 & 0 \\
\hline $10-19$ & $3(5.0)$ & 0 & 0 & 0 \\
\hline $20-29$ & $20(33.33)$ & $11(39.28)$ & $2(50.0)$ & $1(12.5)$ \\
\hline $30-39$ & $24(40.0)$ & $14(50.0)$ & $1(25.0)$ & $3(37.5)$ \\
\hline $40-49$ & $4(6.67)$ & $2(7.14)$ & $1(25)$ & $3(37.5)$ \\
\hline $50-59$ & $3(5.0)$ & $1(3.58)$ & 0 & $1(12.5)$ \\
\hline $60-69$ & $5(8.33)$ & 0 & 0 & 0 \\
\hline
\end{tabular}

The peak age incidence in ano-rectal abscess, perianal sinus/fistula-in-ano, pilonidal sinus, Fournier's gangrene are in the age groups of 20-39 year comprising of73.33\%, 20-39 year comprising of $89.28 \%, 20-29$ year comprising of $50 \%$ and $30-49$ year comprising of $75 \%$ respectively. 
The proportion of cases among the male and female are found to be 2:1, 5:2 and 3:1 in cases of anorectal abscess, fistula-in-ano and pilonidal sinus respectively whereas Fournier's gangrene is exclusively a disease of males.

The prevalence of anorectal abscess in different socioeconomic strata is found out to be $56.6 \%, 33.4 \%, 10 \%$ in the low, average and high strata respectively in our series.

\begin{tabular}{|c|c|c|c|c|}
\hline Name of the Disease & $\begin{array}{c}\text { Ano rectal abscess } \\
(\%)\end{array}$ & $\begin{array}{c}\text { Fistula in ano } \\
(\%)\end{array}$ & $\begin{array}{c}\text { Fournier gangrene } \\
(\%)\end{array}$ & $\begin{array}{c}\text { Pilonidal sinus } \\
(\%)\end{array}$ \\
\hline Pain $\&$ symptoms & $55(91.66)$ & $8(28.57)$ & $8(100)$ & $3(75.0)$ \\
\hline Fever & $15(25.00)$ & $2(7.14)$ & $7(87.5)$ & 0 \\
\hline Discharge & 0 & $28(100)$ & $8(100)$ & $2(50.0)$ \\
\hline Tenesmus & $40(66.66)$ & $4(14.28)$ & $1(12.5)$ & $2(50.0)$ \\
\hline Tender swelling & $54(90.00)$ & $2(7.14)$ & 0 & $3(75.0)$ \\
\hline Constipation & $35(58.33)$ & 0 & 0 & $2(50.0)$ \\
\hline
\end{tabular}

Table-2: Presenting features of different ano-rectal suppurative diseases

Presenting features in cases of anorectal abscess were pain (91.66\%), painful swelling (90\%) followed by tenesmus (66.66\%), constipation (58.33\%) and fever, $(10 \%)$ in our series. In cases of fistula-in-ano they were discharge $(100 \%)$ followed by pain $(28.57 \%)$, tenesmus $(14.28 \%)$, fever $(7.14 \%)$ and tender swelling (7.14\%). In cases of pilonidal sinus they were pain $(75 \%)$, tender swelling $(75 \%)$ followed by discharge (50\%), constipation (50\%) and tenesmus $(50 \%)$. In cases of Fournier's gangrene they were pain (100\%), discharge $(100 \%)$ and fever $(87.5 \%)$ and tenesmus $(12.5 \%)$ to follow.

The prevalence of different types of ano-rectal abscess that is perianal abscess, ischiorectal abscess, pelvi-rectal abscess and submucousal abscess was 20:9:1:0 in our series.

\begin{tabular}{|c|c|c|c|c|}
\hline Symptoms \& sign & Perianal abscess & Ischiorectal abscess & Submucosal abscess & Pelvirectal abscess \\
\hline Pain & $32(80.0)$ & $17(94.44)$ & 0.00 & $1(50.0)$ \\
\hline Fever & $10(25.0)$ & $12(66.66)$ & 0.00 & $2(100.0)$ \\
\hline Discharge & 0.00 & 0.00 & 0.00 & 0.00 \\
\hline Tenderness & $36(90.0)$ & $18(100.0)$ & 0.00 & $1(50.0)$ \\
\hline
\end{tabular}

The differentiating presenting features in cases of perianal abscess were pain/tenderness(90\%), followed by fever(10\%) whereas in cases of ischio-rectal abscess were tenderness(100\%) and pain(94.44\%) followed by fever(66.66\%) whereas in cases of pelvirectal abscess they were fever(100\%) followed by pain/tenderness(50\%) in our series.

Organisms isolated through pus culture in the cases of anorectal abscess were E.coli (66.67\%) followed by staph.aureus (20\%), bacteriods (6.67\%), streptococcus $(3.33 \%)$ and proteus $(3.33 \%)$ in our series. isolation was done through pus culture. It was been found out that in children The organism commonly isolated was staphylococcus aureus in children in all cases whereas in adults most cases were caused by E. coli followed by staph. aureus. 
The recurrence in cases of perianal abscess, ischiorectal abscess and pelvirectal abscess is found out to be 5\%,5.55\% and nil respectively following treatment.

The duration of healing in cases of ischio-rectal abscess was 55.55\% in 10 days, $33.33 \%$ in 12 days and $11.11 \%$ in 13 days after treatment followed.

Out of 33 openings it was found that single, double and triple openings present in 24 comprising of $85.71 \%$, in 3 cases comprising of $10.71 \%$ and in single case comprising of $3.58 \%$ respectively in this series.

Out of total 33 openings located externally, 14 openings and 19 openings occurred anteriorly comprising of $42.42 \%$ and posterior to anus comprising of $57.58 \%$ respectively in this series.

\begin{tabular}{|c|c|c|}
\hline Types of external opening & No. of cases & Correct correlation \\
\hline Anterior & 14 & 12 \\
\hline Posterior & 19 & 15 \\
\hline \multicolumn{2}{|c|}{ Table-4: Accessing Goodsall's rule } \\
\hline
\end{tabular}

The correct correlation of the internal opening according to the external opening in anterior type is $85.71 \%$ and in posterior type is $78.94 \%$.

Out of the 28 cases of fistula-in-ano 16 cases comprising of 57.14\%, 10 cases comprising of $35.71 \%$ and 2 cases comprising of 7.15\% occurred in persons of low socio-economic status, in average/middle socioeconomic status and in high socio-economic status population respectively in this series.

The recurrences of fistula in ano are found in 2 of the cases comprising of $7.14 \%$ in this series.

DISCUSSION: Lunniss $\mathrm{P}$ and Nujent $\mathrm{K}^{1}$ mentioned that perianal abscesses constituted $60 \%$ of all anorectal abscess, ischiorectal abscesses accounted for 30\% of all anorectal abscesses, submucus abscesses accounts for $5 \%$ and another $5 \%$ accounted for by the pelvirectal abscesses. In this series of 60 cases of anorectal abscesses 40 were perianal abscesses constituting 66.66\%. 18 cases were ischiorectal abscess accounting for 30\%. Pelvirectal abscesses accounted for $3.33 \%$ constituting 2 cases. Thus in this series incidence of perianal abscesses is more common, whereas incidence of submucous and pelvirectal abscess is less common.

GRAEME CLARKE et al, in their article fistula-in-ano; A prospective study of 107 cases found out that Goodsall's rule was obeyed by $91 \%$ of posterior fistulae and $69 \%$ of anterior type fistulae. In this series this defers little. Goodsall's rule is obeyed by $85.71 \%$ posterior type of fistula-in-ano and 78.94\% of anterior type of fistula-in-ano. Also it was seen in the series that considering those anterior fistulae which disobeyed Goodsall's rule, the majority did show by curving medially to an anterior midline internal opening similar to typical posterior fistula. In this series out of 6 internal openings which were not correlating with the external openings 4 cases opened in the anterior midline while 2 cases were short of it but was not radial to the external anal opening. 17

NIGEL BARWOOD et al, in their article found that 57\% of fistula-in-ano were posterior type. Also among posterior type of fistula male outnumbers female by more than 3: 1. A higher proportion of female was among the fistula with anterior external opening. In this series it has been found out that male: female incidence for posterior type of fistula-in-ano was 3: 1 and the ratio was male: 
female for anterior type fistula-in-ano was 4: 3 . Thus with some variation, the male: female incidence correlates with those of findings of NIGEL BARWOOD et al. 17

In this series it is found that E coli were isolated in $66.66 \%$ of cases. Staphylococcus aureus was isolated in $20 \%$. Bacteroids isolated in $6.67 \%$, Streptococcus was isolated in $3.33 \%$, proteus was isolated $3.33 \%$ cases. They also have mentioned that E coli constituted $60 \%$, Staphyloccus aureus constituted 23\%. In diminishing frequency, pure cultures of Bacteroids, streptococcus and proteus strains were found. ${ }^{1}$

CONCLUSION: Perianal suppurative disease is no a rare disease. Progress in pharmacology and other specialties have so to say failed to extradicate it.

Of the perianal suppurative disease, anorectal abscess are more common, of the anorectal abscess perianal abscess is most common followed by ischiorectal abscess. Most common presentation is pain, followed by a tender cystic swelling. Common in age group 20-39 years. More common in males and in low socioeconomic group. Most common organism isolated is E. Coli, followed by Staphylococcus aureus. The recurrence rate in perianal abscess is $5 \%$ and in case of ischiorectal abscess it is $5.55 \%$.

Fistula-in-ano followed next to perianal abscesses. Most common presentation is discharge followed by pain and fever. Commonly in males; Most common age of incidence was 20 -39 years of low socioeconomic status group with single posterior external openings most commonly. Goodsall's rule is consistently obeyed by anterior type fistula-in-ano compare to posterior type, anterior type common in females and posterior type in males.

Fournier's gangrene is unique in males. Common age group of incidence is $30-39$ years followed by 40 - 49 years and disease of low socioeconomic status group of patients.

For a perianal abscess, a cruciate incision with deroofing of the abscess cavity is better than a cruciate incision only. For a fistula-in-ano coring out the track with intra-anal sphincterotomy with deroofing of the mucosa and internal sphincter is more satisfactory for cure.

The study of such a short duration and handful of cases may not be very much conclusive. However further study on its aetiopathology and successful management will be much beneficial.

\section{REFERRENCE:}

1. LunnissP, Nujent K. The anus and anal canal. In: Williams Norman S, Bulstrode Christopher J.K, editors: Bailey \& love's short practice of surgery: 26 th edition, Boca Raton, CRC Press, 2013, pp1236-1267.

2. Nelson H. Anus. In: Townseed CM, Beauchamp RD, Evers BM, Mattox KL, editors: Sabiston textbook of surgery: 19thedition, Philadelphia, Saunders, 2012, pp1381-1410.

3. Das S. The rectum and anal canal: A Concise Textbook of Surgery: 6th edition, Kolkata, 2010, pp949-987.

4. Adams T, Yang J, Kondylis LA, Kondylis PD. Long-term outlook after successful fibrin glue ablation of cryptoglandular transsphincteric fistula-in-ano. Dis Colon Rectum. 200; 51: 14881490.

5. Sentovich SM. Fibrin glue for anal fistulas: long-term results. Dis Colon Rectum.2003; 46:498450. 
6. Swinscoe MT, Ventakasubramaniam AK, Jayne DG. Fibrin glue for fistula-in-ano: the evidence reviewed. Tech Coloproctol. 2005; 9:89 -94.

7. Yeung JM, Simpson JA, Tang SW, Armitage NC, Maxwell-Armstrong C. Fibrin glue for the treatment of fistulae-in-ano: a method worth sticking to? [published online ahead of print February 7, 2009] Colorectal Dis. doi: 10.1111/j.1463-1318. 2009.01801.x.

8. Lindsey I, Smilgin-Humphreys MM, Cunningham C, Mortensen NJ, George BD. A randomized, controlled trial of fibrin glue vs. conventional treatment for anal fistula. Dis Colon Rectum. 2002; 45:1608-1615.

9. Kya AJ, Sylla P, Steinhagen R, Steinhagen E, Khaitov S, Ly EK. Collagen fistula plug for the treatment of anal fistulas. Dis Colon Rectum. 2008;51:838-843.

10. Zubaidi A, AL-Obeed O. Anal fistula plug in high fistula-in ano: an early Saudi experience. Dis Colon Rectum. 2009;52: 1584-1588.

11. Champagne BJ, O'Connor LM, Ferguson M, Orangio GR, Schertzer ME, Armstrong DN. Efficacy of anal fistula plug in closure of cryptoglandular fistulas: long-term follow-up. Dis Colon Rectum. 2006;49:1817-1821.

12. Christoforidis D, Etzioni DA, Goldberg SM, Madoff RD, MellgrenA. Treatment of complex anal fistulas with the collagen fistula plug. Dis Colon Rectum. 2008;51:1482-1487.

13. Mitalas LE, Gosselink MP, Zimmerman DD, Schouten WR. Repeat transanal advancement flap repair: impact on the overall healing rate of high transsphincteric fistulas and on fecal continence. Dis Colon Rectum. 2007;50:1508 -1511.

14. Schouten WR, Zimmerman DD, Briel JW. Transanal advancement flap repair of transsphincteric fistulas. Dis Colon Rectum. 1999;42:1419-1422.

15. Zimmerman DD, Briel JW, Gosselink MP, Schouten WR. Anocutaneous advancement flap repair of transsphincteric fistulas. Dis Colon Rectum. 2001;44:1474 -1480..

16. Kelli M, Dunn B, Rothenberger DA: Colon, Rectum and Anus. In: Brunicardi FC, Anderson DK, Biliar TR, Dunn DL, Hunter JG, Matthews JB, Pollock RE, editors: Schwartz's principles of surgery: $9^{\text {th }}$ edition. USA, McGraw-Hill companies, 2010, pp1067, 1068.

17. Nigel Barwood, Graeme Clarke, Sol Levitt, Michael Levitt, Australian and New Zealand Journal of Surgery, February 1997, Volume 67, Issue 2-3, pp 98-102.
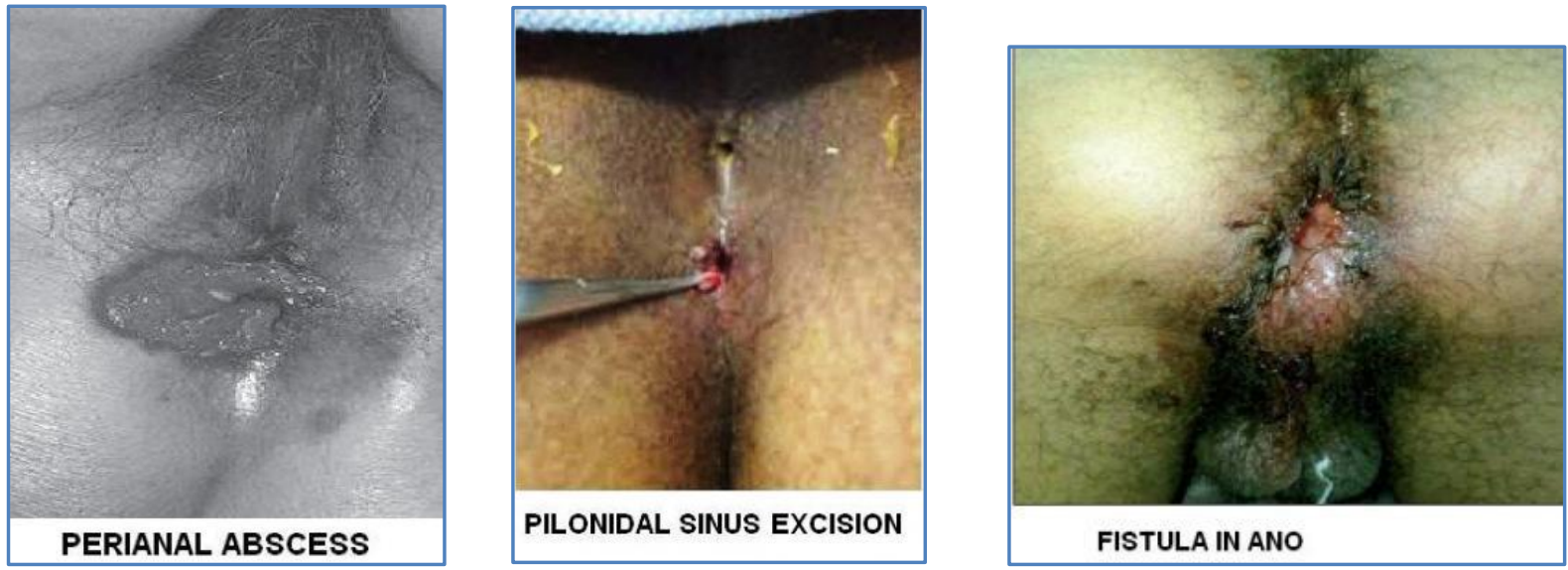


\section{ORIGINAL ARTICLE}

\section{AUTHORS:}

1. Sudhakar Jena

2. Siba Prasad Dash

3. Subhabrata Das

4. Ramanarayan Sahu

\section{PARTICULARS OF CONTRIBUTORS:}

1. JRS, Department of General Surgery, M.K.C.G. M.C.H, Berhampur, Odisha.

2. Associate Professor, Department of General Surgery, M.K.C.G. M.C.H, Berhampur, Odisha.

3. Assistant Professor, Department of General Surgery, M.K.C.G. M.C.H, Berhampur, Odisha.

4. RS, Department of General Surgery, M.K.C.G. M.C.H, Berhampur, Odisha.

\section{NAME ADDRESS EMAIL ID OF THE} CORRESPONDING AUTHOR:

Dr. Sudhakar Jena,

Room No. - 83, PG Hostel - 2,

M.K.C.G. M.C.H, Berhampur,

Odisha - 760004.

Email - reliablesudhakar@gmail.com

Date of Submission: 01/01/2014.

Date of Peer Review: 02/01/2014.

Date of Acceptance: 10/01/2014.

Date of Publishing: 17/01/2014. 